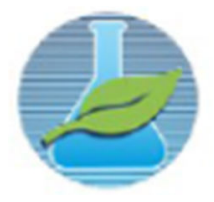

\title{
DETERMINAÇÃO DO COEFICIENTE DE ATRITO PNEU/SOLO DO VEÍCULO BAJA
}

\author{
Rogério Teixeira Lopes \\ Universidade Federal de Viçosa, Departamento de Engenharia de Produção e Mecânica \\ Ph. Rolfs s/n - 36570-000 - Viçosa - MG \\ rogerio.teixeira@ufv.br
}

\section{INTRODUÇÃO}

O coeficiente de aderência entre o pneu/solo $(\mu)$ está relacionado ao atrito disponível ao se realizar processos dinâmicos no veículo, como frenagem, aceleração, absorção de forças laterais, no caso de forças centrípetas em curvas. O seu valor está associado a vários fatores que podem o tornar determinante em um dimensionamento do sistema de freios, fatores como adesão molecular, que depende dos materiais em contato, a integridade dos pneus, pneus desgastados possuem uma menor resistência ao movimento logo derrapam mais, também o tipo de solo no qual se está rodando com o veículo, asfalto, por exemplo, tende a criar um atrito com o pneu muito maior que a terra solta que comumente o baja é testado.

\section{OBJETIVOS}

O teste realizado tem como objetivo encontrar o valor corresponde ao atrito entre o pneu e o solo no momento em que ocorre um processo dinâmico com o veículo, tendo como principal limitação, a simulação real de um terreno de terra solta semelhante à pista de provas das competições BAJA SAE. A determinação desse valor é de extrema importância nos cálculos para dimensionamento do sistema de freios de um veículo visto que quanto maior for o valor desse coeficiente maior será a capacidade de frenagem do veículo em uma menor distância, de um modo geral, reduzirá a derrapagem do veiculo em relação ao solo quando as roda do veículo estiverem travadas.

\section{METODOLOGIA}

O teste consiste basicamente em realizar uma força no veículo BAJA embarcado com o piloto, estando este veículo com as quatro rodas travadas (Fig. 1). Com uma célula de carga e o uso de um software que capture seus dados é possível mensurar a força (Fapli) necessária para o veiculo entrar em movimento.

Através da Equação (1) podemos relacionar as forças existentes no veículo na eminência de trocar do estado estático para o dinâmico.

$$
\begin{gathered}
\text { Fapli }=\text { Fatr } \\
\text { Fatr }=\mu x N
\end{gathered}
$$

Sendo $F_{a t r}$ a força de atrito nas rodas, $\mu$ o coeficiente de atrito entre o pneu e o solo e $N$ a força normal do veículo que nesse caso é igual a massa $(M)$ do veículo multiplicada pela gravidade $(g)$, pela Eq. (3) podemos encontrar o coeficiente de atrito entre o pneu/solo do veículo. 
$\mu=\frac{F a p l i}{M \times g}$

\section{RESULTADOS}

Os valores encontrados através da célula de carga foram plotados em um gráfico de Força $x$ Tempo (Fig. 2), tendo como principal valor para o cálculo do coeficiente de atrito pneu/solo o ponto mais alto desse gráfico, $\mathrm{F}=1765 \mathrm{~N}$, visto que será onde o veículo estará na iminência da troca de estado, passando então de um movimento estático para um movimento dinâmico.

A massa do veículo junto ao piloto foi mensurada utilizando-se uma balança no momento da realização do teste, encontrou-se o valor de $\mathrm{M}=250 \mathrm{~kg}$. Utilizando-se também o valor da gravidade padrão, $\mathrm{g}=9,81 \mathrm{~m} / \mathrm{s}^{2}$ encontrou-se $\mu=0,72$.

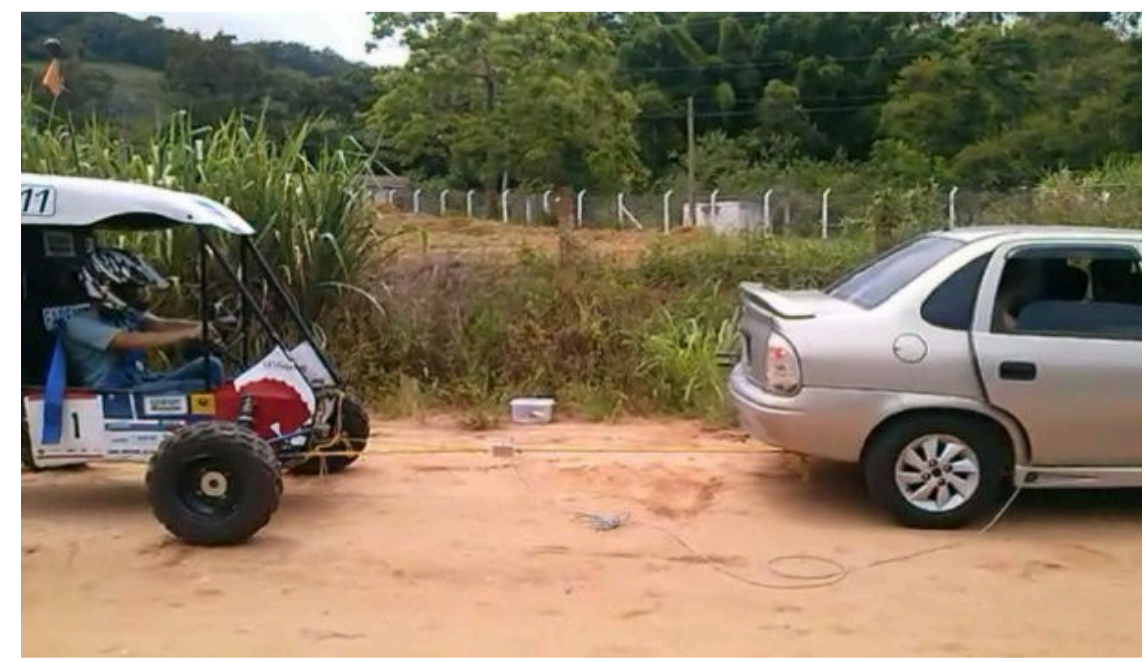

Figura 1 - Montagem do sistema para captura dos dados.

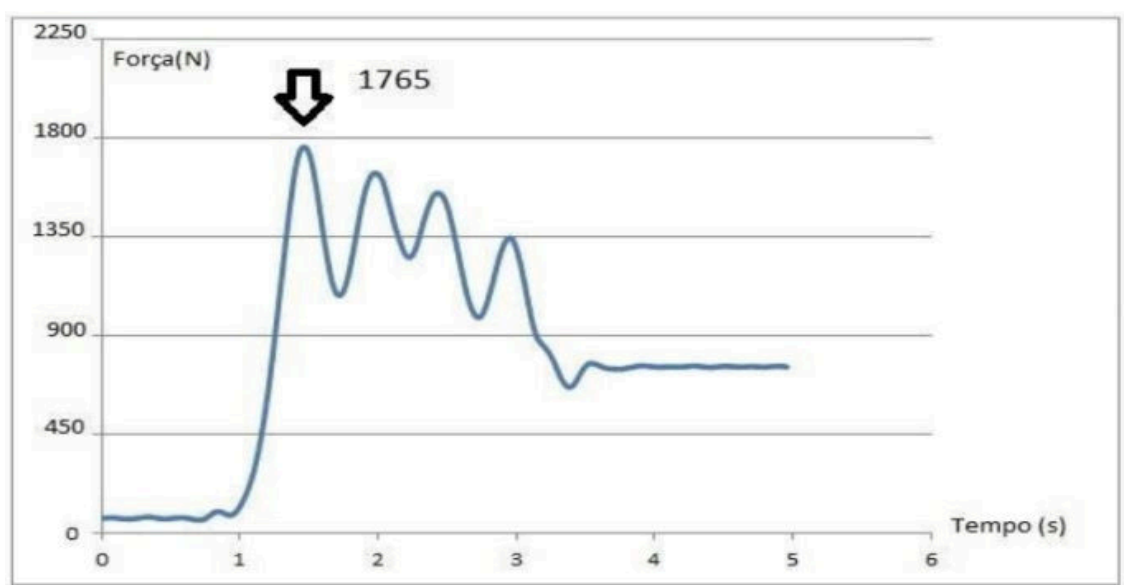

Figura 2 - Gráfico Força x Tempo coletado pela célula de carga.

\section{CONCLUSÃO}

A determinação desse coeficiente de atrito entre o pneu e o solo foi de extrema importância no dimensionamento do veículo uma vez que esse valor de 0,72 encontrado para o coeficiente está acima do valor literário de 0,60 utilizado nos projetos antigos. Essa diferença encontrada tem algumas consequências como, por exemplo, a exigência de uma força maior no pedal de freio pelo piloto para permanecer com as rodas travadas, de forma que um maior coeficiente tende a criar um maior atrito na roda, esse responsável por criar uma força de rotação contraria ao deslocamento do veículo. Como ponto positivo pode-se destacar a distancia de frenagem, visto que um coeficiente de atrito maior faz 
com que o carro pare em uma distancia menor derrapando menos que, por exemplo, um veiculo na qual o coeficiente de atrito entre o pneu e o solo é menor.

\section{AGRADECIMENTOS}

Gostaria de agradecer primeiramente Universidade federal de viçosa, especificamente ao DEP (Departamento de engenharia de Produção e Mecânica) por ceder os equipamentos necessários para a realização do teste e também agradecer a todos os membros da equipe UFVBaja Pererecas que de uma forma ou de outra estiveram envolvidos na realização do teste.

\section{REFERÊNCIAS}

LEAL, L.M., da ROSA, E., NICOLAZZI, L.C. "Uma introdução a modelagem quase-estático de veículos automotores de rodas”. UFSC, Florianópolis, 2001. 